\title{
Adrenal Cortex Adenomatoid Tumor
}

National Cancer Institute

\section{Source}

National Cancer Institute. Adrenal Cortex Adenomatoid Tumor. NCI Thesaurus. Code C48319.

A benign adrenal cortex neoplasm deriving from mesothelial cells. 